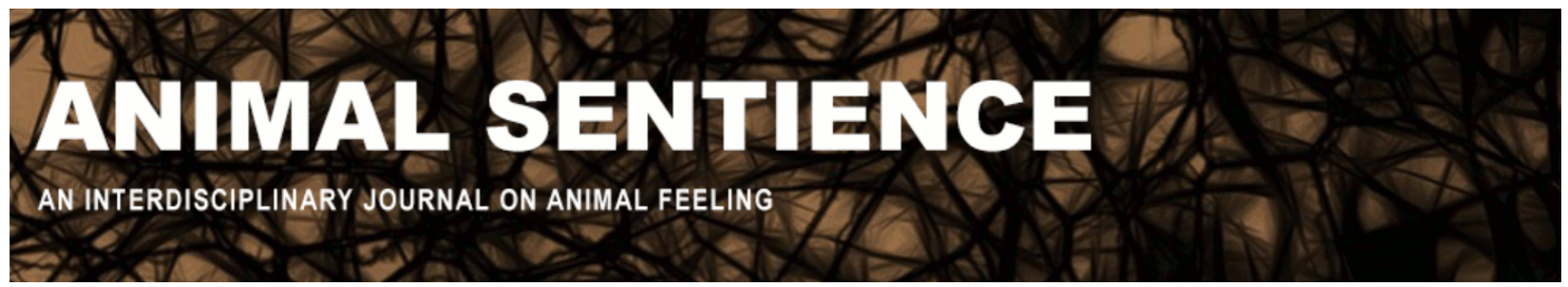

Elwood, Robert W. (2020) Do arthropods respond to noxious stimuli purely by reflex?. Animal Sentience 29(10)

DOI: $10.51291 / 2377-7478.1593$

Date of submission: $2020-06-19$

Date of acceptance: 2020-06-22

(c)

This article has appeared in the journal Animal

Sentience, a peer-reviewed journal on animal

cognition and feeling. It has been made open access,

free for all, by WellBeing International and deposited

in the WBI Studies Repository. For more information,

please contact

wbisr-info@wellbeingintl.org.

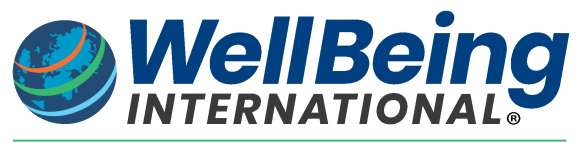

SOLUTIONS FOR PEOPLE, ANIMALS AND ENVIRONMENT 


\title{
Do arthropods respond to noxious stimuli purely by reflex?
}

\author{
Commentary on Mikhalevich \& Powell on Invertebrate Minds
}

\author{
Robert W. Elwood \\ School of Biological Sciences, Queen's University, Belfast, UK
}

\begin{abstract}
Mikhalevich \& Powell (2020) argue that it is wrong to dismiss the idea of sentience in invertebrates. Here, I expand on the evidence for crustaceans responding to noxious stimuli in ways that are not explained by mere reflexes, and that are consistent with pain. I consider the idea that male praying mantids must not feel pain because they may continue to mate whilst being consumed by the female. I finish with thoughts about the idea that because robots may be constructed to act as if they experience pain, the argument that animals might experience pain is diminished.
\end{abstract}

Robert W. Elwood, Emeritus Professor of Animal Behaviour, Queen's University, Belfast, works on pain, informationgathering, motivation, and aggression. $\underline{\text { Website }}$

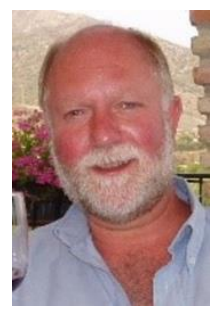

1. Introduction. Mikhalevich \& Powell (2020) argue that arthropods and some other invertebrates have moral value and that welfare concerns should be applied to them rather than just to vertebrates. They outline evidence for sentience in these animals and also examine some of the objections to sentience. The aim of this commentary is to expand first, on some of the evidence as it relates specifically to the experience of pain, and second, on two key objections to the idea of pain in these animals.

2. Non-reflexive responses in decapods. Pain may be described as 'a non-reflexive response to a noxious, potentially tissue-damaging stimulus that alters future behaviour' (Elwood 2019). This definition gets away from the concept of subjective experience or feeling, because that is difficult to access, yet distinguishes it from a mere nociceptive reflex. This distinction is important because the most common argument about potential pain in arthropods is that they only respond to noxious stimuli with nociceptive reflexes and pain need not be inferred. Several experiments, however, have shown that this is not the case, at least in decapod crustaceans. Glass prawns show prolonged and complex grooming of their antennae if they are brushed with noxious chemicals, but this is reduced if they are previously treated with a local anaesthetic (Barr et al. 2008). Shore crabs show prolonged grooming of their eyes or mouthparts if they are brushed with weak acetic acid (Elwood et al. 2016). Hermit crabs might get out of their shells if they receive electric shocks within but are less likely to get out if they have high-quality shells (Elwood \& Appel 2009) or if there is an odour of a potential predator (Magee \& Elwood 2016). These observations of behavioural trade-offs between two motivational systems do not fit with the idea of reflex responses because they clearly show centrally organized decision-making. There are also changes in the behaviour of shore crabs such as swift discrimination between shelters in which electric shock occurs and those that are safe (Magee \& Elwood 2013). Hermit crabs show a heightened motivation to get a new 
shell many hours after receiving a shock within their shell (Elwood \& Appel 2009). Crayfish and amphipods show signs of anxiety after receiving an electric shock and show a shift to low-risk behaviour (Fossat et al. 2014; Perrot-Minnot et al. 2017). Highly valued resources are given up by shore crabs leaving shelters and by hermit crabs abandoning shells, when escaping noxious stimuli; this again indicates the aversive nature of the stimuli used.

These and other experiments show that the immediate responses to noxious stimuli are more than mere reflex; the longer-term changes indicate plasticity in behaviour that allows recovery and minimises further injury. All these observations are consistent with the idea of pain in decapods. Of course, they do not prove that decapods experience pain the same way humans do because it is impossible to access the feelings of nonhuman animals. However, such is the accumulation of studies that it is now impossible to dismiss the idea that pain might be felt. We need a similar experimental approach with insects to determine whether they simply show reflex responses or something more complex in keeping with pain.

3. Praying mantids. Mikhalevich \& Powell note that the idea that insects might experience pain is frequently dismissed because of observations of apparently normal behaviour continuing whilst the insect is being damaged. A common example is a male praying mantid being eaten by the female (there are many video examples on the Web). The male might be attacked by the female after copulation has been initiated and copulation continues whilst the head is eaten, or the area just posterior to the head is chewed through and the head falls off. There are further remarkable examples of courting males being bitten before copulation commences but, remarkably, the male might still manage to make genital contact and successfully copulate after having the head chewed off. Because the male does not struggle, it is argued that the hapless male feels no pain. However, the lack of any escape attempts also suggests that the nociceptive system is not functioning, as there are no reflex responses. By contrast, other examples show females approaching males and initiating a predatory attack before the male initiates courtship. In this situation, the males show vigorous waving and pushing with the legs in apparent attempts to escape, which is consistent with nociception and possibly more complex responses that might indicate pain.

An explanation for these different responses is that male mantids have neuronal systems that promote survival and lessen tissue damage, but to use these to interrupt mating could be disadvantageous. A male that mates even though he loses his life could yet have a high fitness outcome due to the offspring produced. By contrast, one that struggles free after being attacked may not have sired any offspring with that female and may not locate another with whom to mate in the future. Thus, it is not surprising to see males maximise genetic fitness even though some get killed in the process. The observation of some males not struggling during mating when being bitten, but others showing vigorous escape responses when attacked outside of mating, suggests that these copulating males may suppress the neural control of response to tissue damage (Sneddon et al. 2014) in a manner similar to that seen in humans in contact sports. This modulation of responses suggests more than nociceptive reflex and suggests a trade-off between escape and the opportunity to mate. It deserves further investigation.

4. What do robots tell us? Another objection to pain concerns robots that can be made to express responses with similarities to pain responses, and yet the robot does not feel pain. This is often used to argue that arthropods do not experience pain because simple robot systems can produce similar behaviour. However, the function of pain is to enhance fitness 
and has evolved by natural selection. Animals that can experience pain may have less tissue damage and have a greater lifetime reproductive success. Robots have not been subject to natural selection and have no reproductive success. They are made by humans with the aim of mimicking pain responses. Whilst they may be of interest from an engineering point of view, they tell us little about the evolution and function of pain in animals.

\section{References}

Barr, S., Laming, P.R., Dick, J.T.A., \& Elwood, R.W. (2008). Nociception or pain in a decapod crustacean? Animal Behaviour, 75: 745-751.

Elwood, R.W. (2019). Discrimination between nociceptive reflexes and more complex responses consistent with pain in crustaceans. Philosophical Transactions of the Royal Society B, 374: 20190368.

Elwood, R.W., \& Appel, M. (2009). Pain in hermit crabs? Animal Behaviour, 77: 1243-1246.

Elwood, R.W., Dalton, N., \& Riddell, G. (2017). Aversive responses by shore crabs to acetic acid but not to capsaicin. Behavioural Processes, 140: 1-5.

Fossat, P., Bacque-Cazenave. J., De Deurwaerdere, P., Delbecque, J.-P., \& Cattaert, D. (2014). Anxiety-like behavior in crayfish is controlled by serotonin. Science, 344: 1293-1297.

Magee, B., \& Elwood, R.W. (2013). Shock avoidance by discrimination learning in the shore crab (Carcinus maenas) is consistent with a key criterion for pain. Journal of Experimental Biology, 216: 353-358.

Magee, B., \& Elwood, R.W. (2016). Trade-offs between predator avoidance and electric shock avoidance in hermit crabs demonstrate a non-reflexive response to noxious stimuli consistent with prediction of pain. Behavioural Processes, 130: 31-35.

Mikhalevich, I., \& Powell, R. (2020). Minds without spines: Evolutionarily inclusive animal ethics. Animal Sentience 29(1).

Perrot-Minnot, M.-J., Banchetry, L., \& Cezilly, F. (2017). Anxiety-like behaviour increases safety from fish predation in an amphipod crustacea. Royal Society Open Science, 4: 171558.

Sneddon, L.U., Elwood, R.W., Adamo, S.A., \& Leach, M.C. (2014). Defining and assessing animal pain. Animal Behaviour, 97: 202-212. 


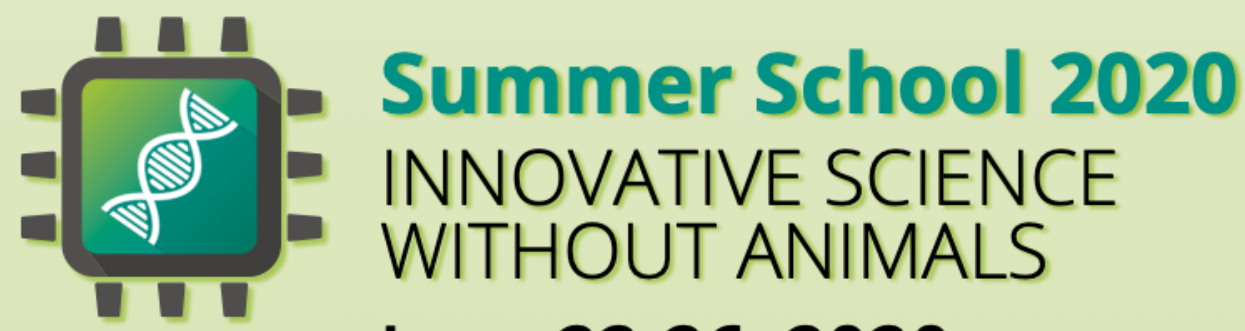

June 22-26, 2020

\section{Online Virtual Conference}

\section{Calling all students and early-career researchers!}

Join us for a FREE conference on innovative approaches in toxicology and biomedical sciences!

\section{This event features:}

Lecture sessions about modern alternatives to the use of animals in toxicology and biomedical sciences

- Virtual laboratory tours

E-poster presentations

- Virtual engagement with speakers and attendees

Deadline to apply for the full program is June 10. Registration for individual lectures is available.

\section{For more information visit InnovativeScience2020.org}

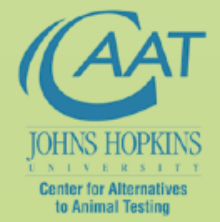

Physicians

for Responsible Medicine

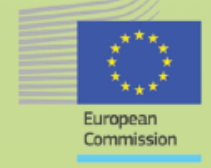

